"C 2019 IEEE. Personal use of this material is permitted. Permission from IEEE must be obtained for all other uses, in any current or future media, including reprinting/republishing this material for advertising or promotional purposes, creating new collective works, for resale or redistribution to servers or lists, or reuse of any copyrighted component of this work in other works." 


\title{
Direct Torque Control Based on a Fast Modeling Method for a Segmented-Rotor Switched Reluctance Motor in HEV Application
}

\author{
Xiaodong Sun, Senior Member, IEEE, Kaikai Diao, Student Member, IEEE, \\ Zebin Yang, Gang Lei, Member, IEEE, Youguang Guo, Senior Member, IEEE, \\ and Jianguo Zhu, Senior Member, IEEE
}

\begin{abstract}
This paper proposes a fast-nonlinear modeling method for the direct torque control (DTC) of a segmented-rotor switched reluctance motor (SSRM) excluding the rotor clamping device. First, the torque-balanced method is used to measure the flux linkage values at five crucial positions. The flux linkage profile of the SSRM is represented by the fourth-order Fourier series based on the measured values. Then the Kriging model is employed to further describe flux linkage and torque characteristics based on the Fourier series. Combination of Fourier series and Kriging model can greatly incorporate their merits and improve the accuracy of the models. Compared with the conventional methods, the finite element analysis data are not required for the modeling process in the proposed method. Finally, simulation and experiments of the DTC and the current chopping control (CCC) methods bash on the modeling method are carried out. The amplitude of flux linkage under DTC can be well controlled while that under $\mathrm{CCC}$ is increased with the enlargement of load torque. Compared with CCC mode, DTC greatly reduces the torque ripple and exhibits the better speed response while the torque per ampere with $\mathrm{CCC}$ mode is higher.
\end{abstract}

Index Terms-Current chopper control, direct torque control, Fourier series, Kriging model, segmented-rotor switched reluctance motor, torque-balanced method.

\section{INTRODUCTION}

$\mathrm{D}$ URING the past decades, much attention has been put to develop the electric vehicles and hybrid electric vehicles (HEVs) in the automobile industry [1]-[3]. To improve the

Manuscript received June 17, 2019; revised August 10, 2019 and September 18, 2019; accepted October 23, 2019. This work was supported by the National Natural Science Foundation of China under Project 51875261, the Natural Science Foundation of Jiangsu Province of China under Projects BK20180046 and BK20170071, the "Qinglan project" of Jiangsu Province, the Key Project of Natural Science Foundation of Jiangsu Higher Education Institutions under Project 17KJA460005, and the Six Categories Talent Peak of Jiangsu Province under Project 2015-XNYQC-003. (Corresponding author: Gang Lei.)

X. Sun and K. Diao are with the Automotive Engineering Research Institute, Jiangsu University, Zhenjiang 212013, China (email: xdsun@ujs.edu.cn, diaokaikai@163.com).

Z. Yang is with the School of Electrical and Information Engineering, Jiangsu University, Zhenjiang 212013, China (e-mail: zbyang@ujs.edu.cn)

G. Lei and Y. Guo are with the School of Electrical and Data Engineering, University of Technology Sydney, NSW 2007, Australia (e-mail: Youguang.Guo-1@uts.edu.au, Gang.Lei@uts.edu.au).

J. Zhu is with the School of Electrical and Information Engineering, University of Sydney, NSW, 2006, Australia (e-mail: jianguo.zhu@sydney.edu.au). stability and fuel economy of the HEVs, the belt-driven starter/generator (BSG) is widely employed [4]. Performance of the BSG motor is crucial to the BSG system. Therefore, it is necessary to improve the performances of BSG motor both in design and control aspects.

The permanent-magnet motors (PMs) [5]-[7] and induction motors (IMs) $[8,9]$ are preliminary alternatives to the BSG. However, the PMs are prone to be demagnetized at high temperature and the IMs have poor speed regulation performance, and both the two types of motor are high cost. Thus, more and more attention has been paid to the switched reluctance motors (SRMs). The advantages of SRMs include high reliability, low cost, and rugged construction [10]-[13], which is suitable for the industry application. The major obstacle for SRMs application is the torque ripple [14]. A variety of configurations have been investigated for SRMs, among them, a new SRM with segmented rotor called segmented-rotor switched reluctance motor (SSRM) was proposed $[15,16]$. And it is proved that the SSRM has lower torque ripple and higher fault-tolerant ability than the conventional SRMs. In the previous work, only the motor topology has been considered, but the control strategy based on the SSRM models has not been investigated.

Several realizable control methods have been investigated in the past decades to improve the overall performances of the SRM. In [17], the average torque control (ATC) system was introduced to reduce the torque ripple of SRMs. Besides, the torque ripple was further reduced by optimizing turn-on and turn-off angles on the basis of ATC system. In [18], the current chopper control (CCC), torque sharing function (TSF) and direct instantaneous torque control (DITC) systems were proposed, but these control methods require complex computation and it is difficult to apply them in real-time systems. The direct torque control (DTC) systems were proposed in [19]. It can be seen that DTC control methods can reduce the torque ripple at low speed range, and the effect of DTC system is more prominent compared with other control strategies. However, these control systems rely on finite element analysis (FEA) data or the entire-cycle experimental data, which is time-consuming and complicated.

The basis of control strategies for the SRM is the models of flux linkage and torque. Finite element method (FEM) and experiment methods have been widely used to establish the 
fundamental models. However, as mentioned above, the computational cost of FEM is always high, especially for some complex structured motors. And the experiment method is time-consuming since it requires abundant measured points. As an alternative, some approximate modeling methods and convenient measured methods have been presented to ease the computational burden for the practical applications, especially in the stage of initial design process. The approximate models can be established based on the achieved samples from FEM or experiments.

A new RBF neural network with boundary value constrains was proposed to approximate models for the SRM based on the calculated flux linkage values from the magnetic field in FEM [20]. In [21], a new method based on an adaptive neural fuzzy inference system for SRM modeling was presented. The indirect method used to measure the static flux linkage and the co-energy method was proposed to calculate the torque characteristics based on the flux linkage data from experiment. Besides, some improved experimental methods have been investigated. For example, in [22], the phase winding was excited by the AC power supply and the flux linkage was calculated by the steady-state terminal voltage and the line current. These above methods based on the experiment data and require locking devices and the measurement accuracy cannot be ensured for high power motors. In addition, precise position sensor is indispensable and the measurement process is time-consuming. The method to measure the flux linkage for the four-phase SRM without rotor clamping devices was firstly proposed in [23]. And in [24], it was extended to the application of a three-phase SRM.

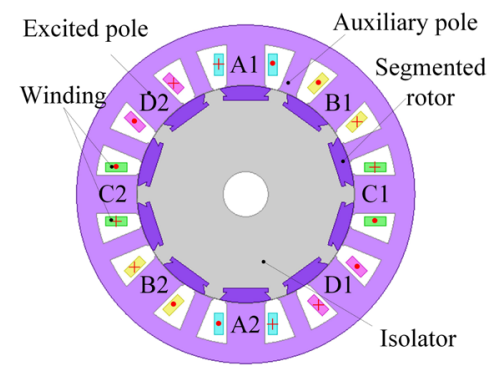

Fig. 1. Structure of a 16/10 SSRM.

Based on these researches, in this paper, an improved method was applied to the SSRM. The measured results of flux linkage were further used in the DTC system for the practical application. This work adopts the torque-balanced method [25] to acquire the flux linkage values of the specific positions for the SSRM without using any rotor clamping device. The initial static flux linkage and torque curves of the SSRM are calculated by the fourth-order Fourier series, and the final nonlinear SSRM modeling of DTC system is further built by the Kriging model. The basic equation, structure, and flux-linkage calculations and nonlinear modeling of the SSRM are introduced in Section II. DTC theory is briefly highlighted in Section III. Section IV describes the simulation results of DTC and CCC systems, and the experiment results for the verification, followed by the conclusions.

\section{SSRM MODELING}

In this section, the flux linkage and torque models of the SSRM are obtained. First, the mathematic model and the specifications of the SSRM are presented. Second, the torque-balanced method excluding the rotor clamping devices is taken to achieve the data of some specific positions where the static torque is zero. Then, based on the torque-balanced method, the approximated models of flux linkage and torque are established by the Fourier series. Finally, to improve the accuracy of the approximated models and overcome the main drawback of the Fourier series, further detailed models are expressed by the Kriging model.

\section{A. Mathematic model and specification of SSRM}

According to the basic voltage equation of conventional SRMs, the voltage of phase $k$ for the studied SSRM is

$$
U_{k}=R_{k} i_{k}+\frac{d \psi_{k}(i, \theta)}{d t}
$$

where $U_{k}, R_{k}, i_{k}$, and $\Psi_{k}$ are the voltage, resistance, current and flux linkage of phase $k$, respectively.

Hence, the flux linkage of the SSRM can be achieved from

$$
\psi_{k}=\int\left(U_{k}-R_{k} i_{k}\right) d t .
$$

The mechanical motion equation of the SSRM can be described as

$$
J \frac{d \omega}{d t}=T_{e}-T_{L}-B \omega
$$

where $J$ is the rotational inertia, $\omega$ is the speed of the motor, $\omega=d \theta / d t, T_{e}$ is the sum of phase torques, $T_{L}$ is the load torque, and $B$ is the coefficient of friction.

The structure of the studied 16/10 SSRM is shown in Fig. 1. The stator of this SSRM is composed of excited teeth and auxiliary teeth, and the rotor is made up of a series of discrete segmented-rotors. The winding connection style of the SSRM is NSNSNSNS. The rated power, speed and voltage of the SSRM are $1.8 \mathrm{~kW}, 6000 \mathrm{r} / \mathrm{min}$ and $60 \mathrm{~V}$, respectively [29]. In addition, the specifications of the SSRM are given in Table I.

TABLE I

SPECIFICATIONS OF THE SSRM

\begin{tabular}{llll}
\hline \hline Parameters & Value & Parameters & Value \\
\hline Stator pole number & 16 & Rotor pole number & 10 \\
Outer radius of stator & $64 \mathrm{~mm}$ & Outer radius of rotor & $41 \mathrm{~mm}$ \\
Stator pole arc & $21.375^{\circ} / 10.69^{\circ}$ & Rotor pole arc & $26.64^{\circ}$ \\
Stator yoke thickness & $8 \mathrm{~mm}$ & Diameter of axle & $17 \mathrm{~mm}$ \\
Length of air-gap & $0.25 \mathrm{~mm}$ & Length of Stack & $80 \mathrm{~mm}$ \\
Number of turns & 24 & Resistance per phase & $0.035 \Omega$ \\
\hline \hline
\end{tabular}

\section{B. Torque-balanced method for SSRM}

The flux linkage and torque curves of the studied SSRM can be obtained from the Ansys/Maxwell to build the nonlinear model which requires huge computational cost. Besides, the impacts of manufacturing errors and end effect are not taken into consideration in the FEA model. Thus, experimental method achieving the flux linkage and torque values is more reliable since it is more practical. As a result, the torque-balanced method [23] is used to build the nonlinear 
model of the studied SSRM excluding rotor clamping devices in this paper.

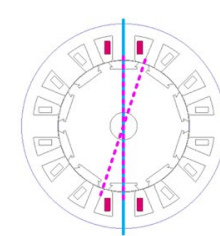

(a)

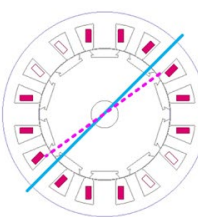

(e)

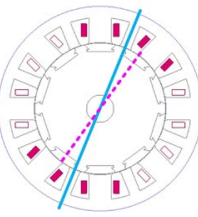

(b)

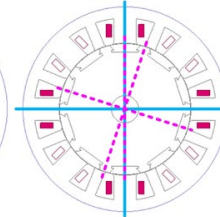

(c)

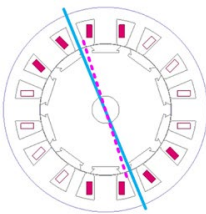

(d)

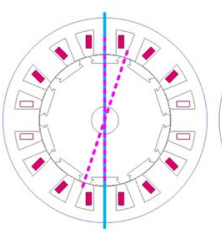

(f)

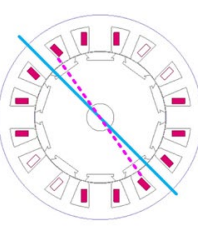

(g)

Symmetrical line of excited phase

Symmetrical line of rotor

Fig. 2. Illustration of positions where torque is zero. (a) Phase A, (b) Phases A and B, (c) Phases A and C, (d) Phases A and D, (e) Phases A, B, and C, and (f) Phases A, B, and D, (g) Phases A, C, and D, and (h) Phases A, B, C, and D are excited, respectively.

The illustration of torque characteristic of the SSRM with different numbers of phase excitation is given in Fig. 2. Considering the symmetry of flux linkage, only half of the cycle, i.e. $0 \sim 18^{\circ}$, is investigated in the proposed torque-balanced method. When the symmetrical lines of excited phases and rotor are overlapping, the torque at this position is zero. Thus, the angle which is less than $18^{\circ}$ between the two proposed lines is the position where the torque is zero. Therefore, these positions can be regarded as balanced positions. All the torque-balanced torque positions and their corresponding excited modes are displayed in Table I, which are corresponding to Fig. 2.

TABLE II

DisPlay OF ALl THE TORQUE-BALANCED POSITIONS

\begin{tabular}{ll}
\hline \hline The excited modes & Torque-balanced positions \\
\hline Phase A & $0^{\circ}, 18^{\circ}$ \\
Phases A, B & $13.5^{\circ}$ \\
Phases A, C & $0^{\circ}, 18^{\circ}$ \\
Phases A, D & $4.5^{\circ}$ \\
Phases A, B, C & $9^{\circ}$ \\
Phases A, B, D & $0^{\circ}, 18^{\circ}$ \\
Phases A, C, D & $9^{\circ}$ \\
Phases A, B, C, D & $0^{\circ}, 9^{\circ}, 18^{\circ}$ \\
\hline \hline
\end{tabular}

The flux linkage curve at the balanced positions can be obtained by applying the same excitation. During the measurement, the PC generates the command for the dSPACE, and the dSPACE supply the drive signals to the asymmetric half-bridge converter to govern the excitations of each phases. All the voltage and current data are recorded by the digital storage oscilloscope to calculate the flux linkage by (2). The measurement errors of resistance and current will directly affect the calculated flux linkage, if the resistance $R_{k}$ or the current $i_{k}$ is larger than the actual value, the flux linkage $\psi_{k}$ will be smaller.

Fig. 3 presents the experiments results of the torque balance method without the rotor clamping device and the conventional measured method with the rotor clamping method to verify the effectiveness and the accuracy of the proposed method. The difference between the two methods at each torque-balanced position is less than $2 \%$, thus the results achieved from the proposed method are reliable.

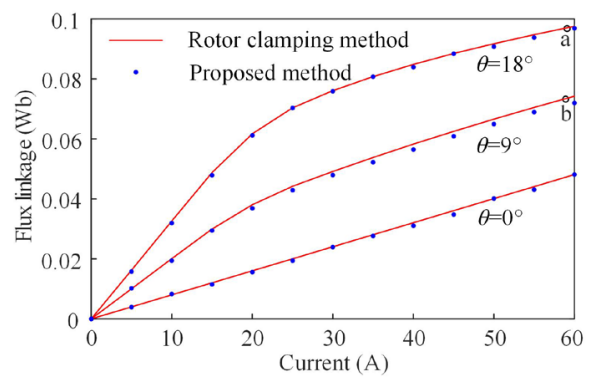

Fig. 3. Comparison of flux linkage curves with the proposed method.

\section{Fourier series flux linkage model}

The flux linkage model of the SSRM can be expressed by the Fourier series [27]

$$
\hat{\psi}(i, \theta)=\sum_{n=0}^{\infty} h_{n}(i) \cos \left(n N_{r} \theta\right)
$$

where $h_{n}(i)$ is the Fourier series coefficients, and $N_{r}$ is the number of rotor poles of the SSRM.

Commonly, the flux linkage of an SRM is modeled by using a simplified second-order Fourier series [23] as

$$
\hat{\psi}(i, \theta)=h_{0}(i)+h_{1}(i) \cos \left(N_{r} \theta\right)+h_{2}(i) \cos \left(2 N_{r} \theta\right)
$$

In (5), the data achieved from three positions is required. Therefore, the relationship between the coefficients and the measured flux linkage of the SSRM at three different positions can be described as

$$
\left[\begin{array}{l}
h_{0}(i) \\
h_{1}(i) \\
h_{2}(i)
\end{array}\right]=\left[\begin{array}{ccc}
1 & 1 & 1 \\
1 & 0 & -1 \\
1 & -1 & 1
\end{array}\right]^{-1}\left[\begin{array}{l}
\psi_{1}(i) \\
\psi_{2}(i) \\
\psi_{3}(i)
\end{array}\right] .
$$

where $\psi_{1}(i), \psi_{2}(i)$ and $\psi_{3}(i)$ are the flux linkage curves at $0^{\circ}, 9^{\circ}$ and $18^{\circ}$, respectively.

Fig. 4 shows the flux linkage characteristic by using the second-order Fourier series. As shown in Fig. 4, it has two wave crests on the surface, which is different from the conventional shape of flux linkage since it only exists one aligned position. To validate the accuracy of the approximate model, root mean square error (RMSE) is calculated, and it is defined as

$$
\mathrm{RMSE}=\left[\frac{1}{N_{e}} \sum_{i=1}^{N_{e}}(\psi(i, \theta)-\hat{\psi}(i, \theta)]^{1 / 2}\right.
$$

where $N_{e}$ is the number of samples. The values of $\psi(i, \theta)$ are achieved from FEA.

The RMSE value of the second-order Fourier series is 0.0067 , and it is obvious in the figure that the values around $18^{\circ}$ lack accuracy. Thus, higher-order Fourier series is taken to develop the accuracy of the model. Besides the mentioned position used in the second-order Fourier series, the flux linkage values of the other two positions, i.e., $4.5^{\circ}$ and $13.5^{\circ}$, 
can also be achieved by experiments. Furthermore, the fourth-order Fourier model is established as

$$
\hat{\psi}(i, \theta)=\sum_{n=0}^{4} h_{n}(i) \cos \left(n N_{r} \theta\right)
$$

Relationship between coefficients and the flux linkage at specific positions can be described as

$$
\left[\begin{array}{l}
h_{0}(i) \\
h_{1}(i) \\
h_{2}(i) \\
h_{3}(i) \\
h_{4}(i)
\end{array}\right]=\left[\begin{array}{ccccc}
1 & 1 & 1 & 1 & 1 \\
1 & 0 & -1 & 0 & 1 \\
1 & -1 & 1 & -1 & 1 \\
1 & \sqrt{2} / 2 & 0 & -\sqrt{2} / 2 & -1 \\
1 & -\sqrt{2} / 2 & 0 & \sqrt{2} / 2 & -1
\end{array}\right]^{-1}\left[\begin{array}{l}
\psi_{1}(i) \\
\psi_{2}(i) \\
\psi_{3}(i) \\
\psi_{4}(i) \\
\psi_{5}(i)
\end{array}\right]
$$

where $\psi_{4}(i)$ and $\psi_{5}(i)$ are the flux linkage curves at $4.5^{\circ}$ and $13.5^{\circ}$, respectively.

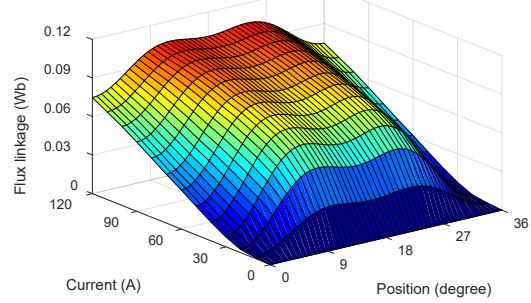

Fig. 4. Flux linkage model from second-order Fourier series.

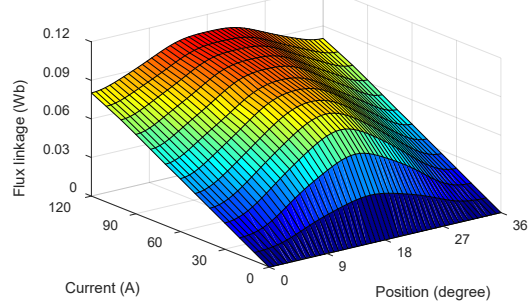

(a)

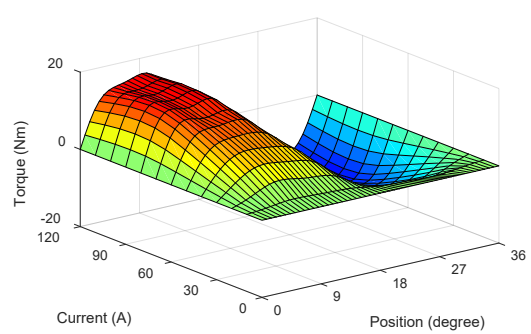

(b)

Fig. 5. Approximate models from fourth-order Fourier series. (a) Flux linkage model. (b) Torque model.

Flux linkage model achieved from the fourth-order Fourier series is shown in Fig. 5(a). The RMSE value of this model is 0.00064 , which is more accurate and acceptable. According to (1), the instantaneous torque of the studied SSRM has been derived in detail in the literature [25], which can be given as

$$
T \approx i \cdot \frac{\partial \psi(i, \theta)}{\partial \theta} .
$$

Then, the torque model is established according to (8) and (10), as shown in Fig. 5(b). The greatest advantage of the
Fourier series is that the torque model can be obtained from the flux linkage model by the mathematic expression when using the torque balance method. However, its main drawback is that it only expresses the relationship between angles and the flux linkage but cannot approximate the model of flux linkage related to the detailed current values. Thus, establishing the detailed model based on the Fourier-series method is the next step.

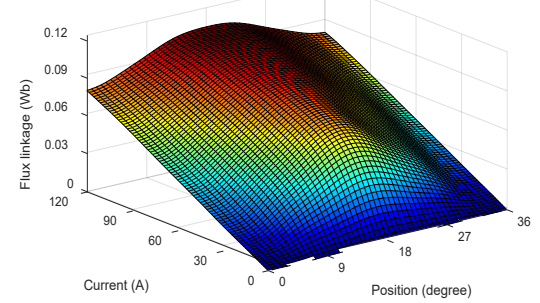

(a)

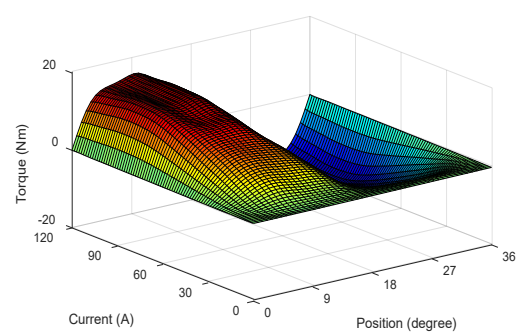

(b)

Fig. 6. Kriging models. (a) Flux linkage model. (b) Torque model.

Step 1: Obtain experimental flux linkage data by using
torque balanced method
1) achieve data at $0,9,18$ by exciting all the phases
2) achieve data at 4.5 by exciting phases A and B
3) achieve data at 13.5 by exciting phases A and D
4) send the achieved data to the next step

Step 2: Establish initial flux linkage and torque models by fourth-order Fourier series

1) set up flux linkage model by (8)

2) set up torque model by (10)

3 ) send the data from the initial approximate models to the next step

Step 3: Establish finial approximate flux linkage and torque models by using Kriging model

Fig. 7. Flowchart of the model building.

\section{Kriging model}

Four kinds of approximate models, namely response surface model (RSM), radial basis function (RBF) model, Kriging model and artificial neural network (ANN) model, which are widely used in the design and optimization of electromagnetic devices [28]. The Kriging model will be investigated in this paper for its consideration of mean trend term and variances of the respond.

Given $\mathrm{n}$ sample points $\left\{\mathrm{x}_{1}, \mathrm{x}_{2}, \ldots, \mathrm{x}_{\mathrm{n}}\right\}$ and their responses $\left\{\mathrm{y}\left(\mathrm{x}_{1}\right), \mathrm{y}\left(\mathrm{x}_{2}\right), \ldots, \mathrm{y}\left(\mathrm{x}_{\mathrm{n}}\right)\right.$, for an input $\mathbf{x}$, the response $\mathrm{y}(\mathbf{x})$ of the Kriging model can be expressed as 


$$
\hat{y}(\mathbf{x})=F(\boldsymbol{\beta}, \mathbf{x})+z(\mathbf{x})
$$

where $F(\boldsymbol{\beta}, \mathbf{x})$ is the regression model and $\mathrm{z}(\mathbf{x})$ is a random error term used for the modeling of local deviation. $F(\boldsymbol{\beta}, \mathbf{x})$ is represented as

$$
F(\boldsymbol{\beta}, \mathbf{x})=\beta_{1} f_{1}(\mathrm{x})+\cdots+\beta_{p} f_{p}(\mathrm{x})=f(\mathbf{x})^{T} \boldsymbol{\beta}
$$

The coefficients $\beta_{\mathrm{k}}$ are regression parameters and $f(\mathrm{x})$ is a known approximation model. $\mathbf{z}(\mathbf{x})$ is usually assumed to be a vector with mean of zero, covariance $\sigma^{2}$, and covariance matrix $\operatorname{cov}_{i j}$ as

$$
\operatorname{cov}_{i j}=\sigma^{2} \mathbf{R}\left(\theta, \mathrm{x}_{i}, \mathrm{x}_{j}\right)
$$

where $\mathbf{R}\left(\theta, x_{i}, x_{j}\right.$,) is the correlation model with parameters $\theta$. the predictor of $\mathrm{y}(\mathbf{x})$ and parameter $\boldsymbol{\beta}$ can be expressed as

$$
\begin{gathered}
\hat{y}(\mathbf{x})=r^{T} \mathbf{R}^{-1} \mathbf{y}-\left(\mathbf{F}^{T} \mathbf{R}^{-1} r-f\right)^{T} \hat{\boldsymbol{\beta}} \\
\hat{\boldsymbol{\beta}}=\left(\mathbf{F}^{T} \mathbf{R}^{-1} \mathbf{F}\right)^{-1} \mathbf{F}^{T} \mathbf{R}^{-1} \mathbf{y}
\end{gathered}
$$

where $\mathbf{F}, r(\mathbf{x})$, and $\mathbf{y}$ are defined as

$$
\begin{gathered}
\mathbf{F}=\left[f\left(\mathrm{x}_{1}\right) \cdots f\left(\mathrm{x}_{n}\right)\right]^{T} \\
r(\mathbf{x})=\left[\mathbf{R}\left(\theta, \mathrm{x}_{1}, \mathrm{x}\right) \cdots \mathbf{R}\left(\theta, \mathrm{x}_{n}, \mathrm{x}\right)\right]^{T} \\
\mathbf{y}=\left[y\left(\mathrm{x}_{1}\right), y\left(\mathrm{x}_{2}\right), \cdots y\left(\mathrm{x}_{n}\right)\right]^{T} .
\end{gathered}
$$

The Kriging models of flux linkage and torque based on the data from the fourth-order Fourier series are shown in Fig. 6. And the flowchart of the model building is illustrated step by step in Fig. 7.

TABLE III

TIME COMPARISON

\begin{tabular}{ccccc}
\hline \hline FEM & Experiments & \multicolumn{3}{c}{ Proposed method } \\
\hline & & $\begin{array}{c}\text { Torque- } \\
\text { balanced }\end{array}$ & $\begin{array}{c}\text { Fourier } \\
\text { series }\end{array}$ & $\begin{array}{c}\text { Kriging } \\
\text { model }\end{array}$ \\
\cline { 3 - 5 } & $216 \mathrm{~min}$ & $15 \mathrm{~min}$ & $0.03 \mathrm{~s}$ & $4.87 \mathrm{~s}$ \\
\hline \hline
\end{tabular}

\section{E. Comparison of time}

To further show the advance in speed of the proposed method, the comparison of time of FEM and experiment methods, and the proposed method is shown in Table III. As the computational time of each FEM model under a certain current level is about 4 min and 24 current levels are divided in the range $0 \sim 120 \mathrm{~A}$, thus, it requires about $96 \mathrm{~min}$ in total. The measured time of flux linkage for each position is about $3 \mathrm{~min}$. For the experimental method, 72 sets are measured in one period and $216 \mathrm{~min}$ is required in total. In the proposed method, only the data at five positions are utilized, thus just about 15 min is spent to measure the flux linkage. Besides, the computational time of the Fourier series and Kriging model are $0.03 \mathrm{~s}$ and $4.87 \mathrm{~s}$, respectively, which can be neglected compared with the time for torque-balanced method. It can be found that the proposed method costs the minimal time among the three methods, which is only $15.6 \%$ and $7 \%$ of the FEM and experiment methods in one cycle, respectively.

\section{III.DTC SYSTEM FOR THE FOUR-PHASE SSRM}

\section{A. Theory of the DTC system}

From (1), the flux linkage can be expressed as

$$
d \psi=(U-R i) d t
$$

Neglecting the phase resistance of the SSRM, (19) can be revised as

$$
\psi(k)=\psi(k-1)+U(k) d t
$$
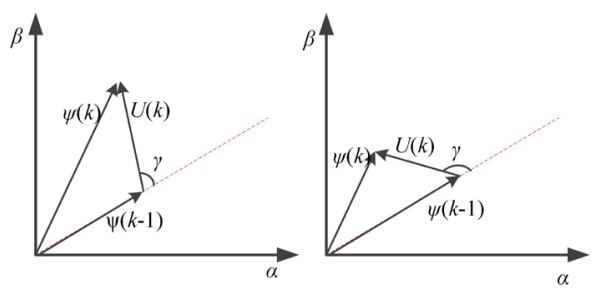

Fig. 8. Relationship curve between stator flux linkage and voltage vector.

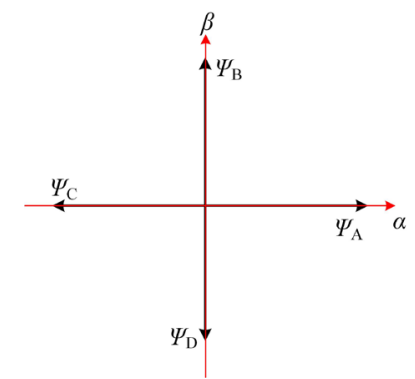

Fig. 9. Diagram of flux linkage transform.
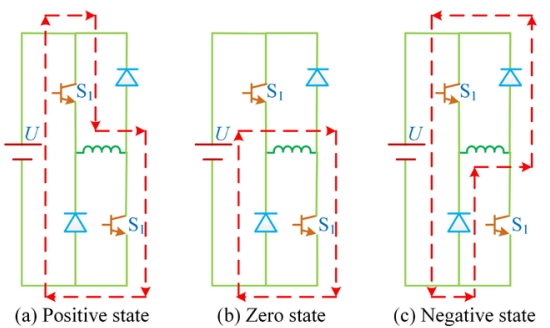

Fig. 10. Switch states of one phase in the asymmetric half-bridge power converter.

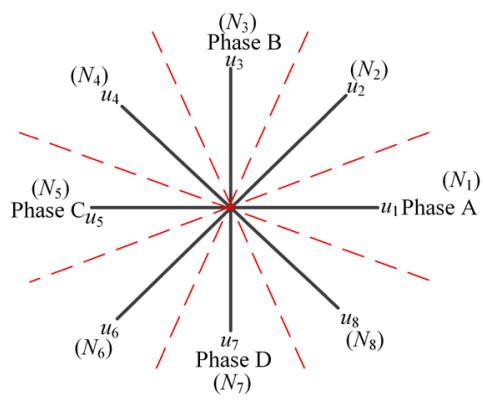

Fig. 11. Basic voltage vectors of the DTC system.

It can be known from (20) that the changed direction of the flux linkage vector is consistent with the direction of voltage vector action. The relationship curve between the stator flux linkage and the voltage vector is shown in Fig. 8. As shown, when the absolute value of the angle $\gamma$ between the flux linkage $\psi(k-1)$ and the voltage vectors $U(k)$ is less than $90^{\circ}$, applying a voltage vector can increase the amplitude of the stator flux linkage $\psi(k)$. On the other hand, when the angle is more than $90^{\circ}$, it will decrease the amplitude of the stator flux linkage $\psi(k)$. 
The main idea of DTC system is to control the voltage vector to limit the amplitude of torque and flux linkage around the given range, thus, the torque ripple can be greatly reduced.

The diagram of flux linkage transform is given in Fig. 9. As shown, $\Psi_{\alpha}$ and $\Psi_{\beta}$ are expressed as

$$
\left\{\begin{array}{l}
\psi_{\alpha}=\psi_{A}-\psi_{C} \\
\psi_{\beta}=\psi_{B}-\psi_{D}
\end{array}\right.
$$

where $\Psi_{\alpha}$ and $\Psi_{\beta}$ are flux linkage on the $\alpha$ and $\beta$ axes, respectively, and $\Psi_{k}$ is the flux linkage of phase $k$.

The amplitude of flux linkage can be expressed as

$$
\psi_{s}=\sqrt{\psi_{\alpha}^{2}+\psi_{\beta}^{2}}
$$

The angle between the flux linkage vector and the $\alpha$ axis is given as

$$
\delta=\arctan \frac{\psi_{\beta}}{\psi_{\alpha}}
$$

\section{B. Principle of the DTC system for SSRM}

Fig. 10 shows the three types of switch states of one phase in the asymmetric half-bridge power converter. As shown, the positive state means both the switches are on, the zero state means only one of the switches is off, and the negative state means the state that both switches are off.

Fig. 11 introduces the basic voltage vectors used for the DTC system. As shown, the space voltage vectors area is divided into eight sectors. The flux linkage and torque can be controlled by the suitable space voltage vectors. In addition, there are only four different combinations of flux linkage and torque variation. Table IV lists the switching table for the basic voltage vector. The upward arrow indicates an increase in the value, and the downward arrow indicates a decrease in the value.

TABLE IV

SWITCHING TABLE FOR BASIC VOLTAGE VeCTOR

\begin{tabular}{ccccc}
\hline \hline Flux-linkage position & $T \downarrow \Psi \downarrow$ & $T \downarrow \Psi \uparrow$ & $T \uparrow \Psi \downarrow$ & $T \uparrow \Psi \uparrow$ \\
\hline $\mathrm{N}_{1}$ & $u_{6}$ & $u_{8}$ & $u_{4}$ & $u_{2}$ \\
$\mathrm{~N}_{2}$ & $u_{7}$ & $u_{1}$ & $u_{5}$ & $u_{3}$ \\
$\mathrm{~N}_{3}$ & $u_{8}$ & $u_{2}$ & $u_{6}$ & $u_{4}$ \\
$\mathrm{~N}_{4}$ & $u_{1}$ & $u_{3}$ & $u_{7}$ & $u_{5}$ \\
$\mathrm{~N}_{5}$ & $u_{2}$ & $u_{4}$ & $u_{8}$ & $u_{6}$ \\
$\mathrm{~N}_{6}$ & $u_{3}$ & $u_{5}$ & $u_{1}$ & $u_{7}$ \\
$\mathrm{~N}_{7}$ & $u_{4}$ & $u_{6}$ & $u_{2}$ & $u_{8}$ \\
$\mathrm{~N}_{8}$ & $u_{5}$ & $u_{7}$ & $u_{3}$ & $u_{1}$ \\
\hline \hline
\end{tabular}

\section{IV.SIMULATION RESULTS}

Since the main drawback of the SRM is the high torque ripple in the low speed range, it is necessary to research the effect of the proposed DTC method on torque ripple. The CCC method is the commonly used control strategy of SRM in the low speed, in order to clearly show the suppression effect on the torque ripple of the studied SSRM using the DTC system, the simulation results of the CCC system are given for comparison. The block diagrams of DTC and CCC systems are presented in Fig. 12, where $n, T, i, \theta$ and $\psi$ represent the speed, torque, current, angle and flux linkage, respectively. The flux modular in Fig. 12(a) represents the calculation modular of flux linkage according to equations 21,22 , and 23 . The input of this modular is the flux linkage of each phase. The parameters in the PI controllers are tuned by the genetic algorithm. The best values of the PI controller coefficients are determined according to the difference between the stable speed and the given speed. The values which exhibit smallest difference between the two speeds are selected as the best coefficients. The CCC results are achieved under full closed-loop of speed, and the turn-on and turn-off angles are set as $-3^{\circ}$ and $12^{\circ}$, respectively. The comparison diagram of the flux-linkage vector locus is given in Fig. 13. The given reference flux linkage in DTC is $0.5 \mathrm{~Wb}$ according to the load torque. As shown, the flux linkage vector trajectory of the CCC system moves along an approximate quadrilateral trajectory, which will result to the torque fluctuations. While the flux linkage vector trajectory of the DTC system moves along an approximate circular trajectory. The flux linkage trajectory of the CCC system fluctuates wildly while the flux linkage amplitude of the DTC system fluctuates slightly. Thus, the flux linkage is well controlled within the hysteresis width under the DTC system.

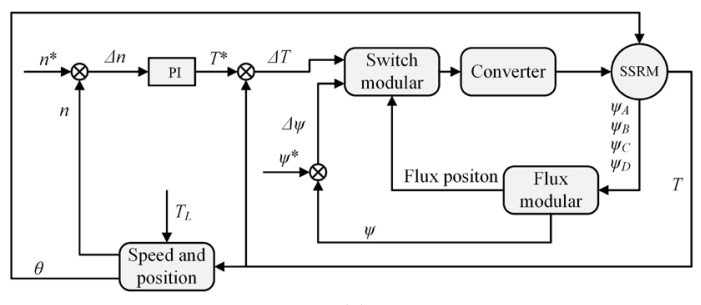

(a)

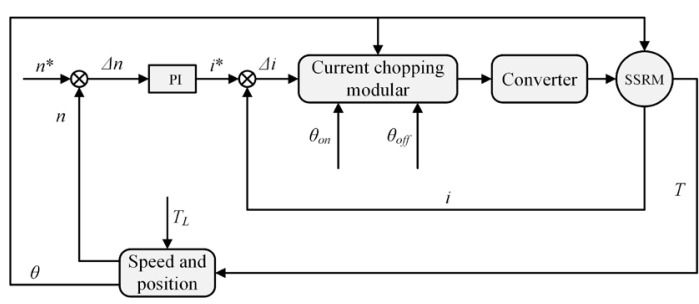

(b)

Fig. 12. Block diagram. (a) DTC. (b) CCC.

The torque ripple of SSRM is expressed as [25]

$$
k_{T}=\frac{T_{\max }-T_{\min }}{T_{\text {avg }}} \times 100 \%
$$

where $k_{T}$ is the torque ripple coefficient, $T_{\max }$ is the maximum torque, $T_{\min }$ is the minimum torque, and $T_{\text {avg }}$ is the average torque.

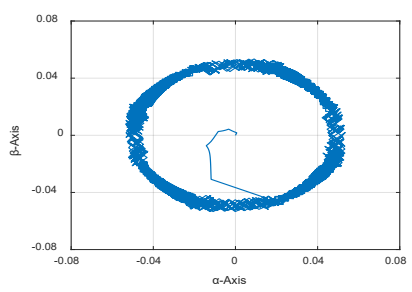

(a)

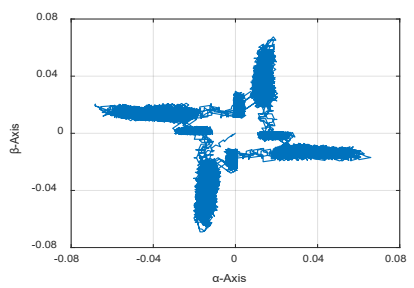

(b)
Fig. 13. Comparison of flux linkage vector locus. (a) DTC and (b) CCC under 3 $\mathrm{Nm}$ at $200 \mathrm{r} / \mathrm{min}$. 


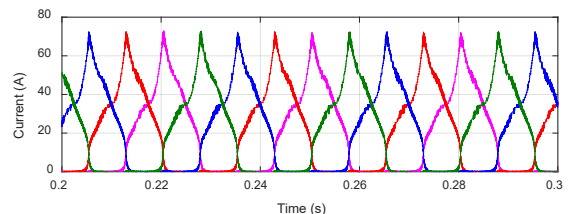

(a)

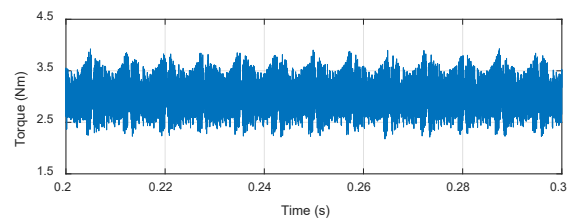

(b)

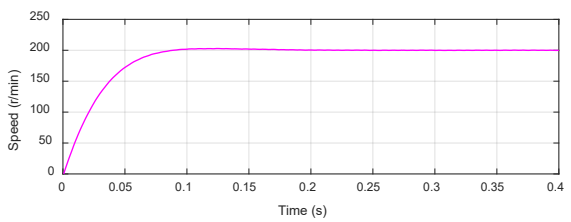

(c)

Fig. 14. Simulation results of DTC under $3 \mathrm{Nm}$ at $200 \mathrm{r} / \mathrm{min}$. (a) Current. (b) Torque. (c) Speed.

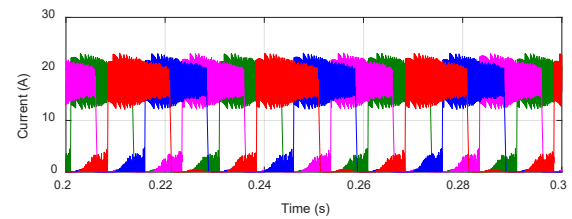

(a)

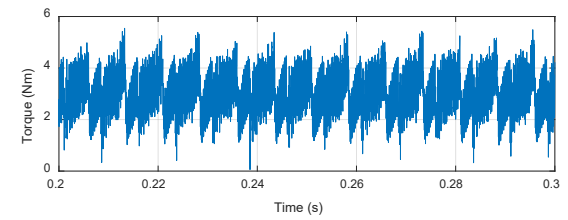

(b)

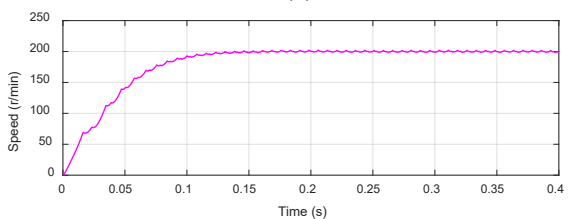

(c)

Fig. 15. Simulation results of CCC under $3 \mathrm{Nm}$ at $200 \mathrm{r} / \mathrm{min}$. (a) Current. (b) Torque. (c) Speed.

Figs. 14 and 15 show the current, torque, and speed responses of DTC and CCC control methods under $3 \mathrm{Nm}$ at 200 $\mathrm{r} / \mathrm{min}$. The peak current in DTC system is higher than that in $\mathrm{CCC}$ system. The chopping current in CCC system is about 20 A achieved by the PI controller. The current limit in CCC system is better controlled than the DTC system. The maximum and minimum torques of DTC are $3.90 \mathrm{Nm}$ and $2.17 \mathrm{Nm}$, while those of CCC system are $5.62 \mathrm{Nm}$ and $0.30 \mathrm{Nm}$. Furthermore, the torque ripple of DTC is $57.28 \%$ while that of CCC is 175.58 $\%$. It means that DTC system can reduce the torque ripple by $67.37 \%$ compared with CCC system, and the torque values can be well control around $3 \mathrm{Nm}$. Compared with CCC system, the rise of SSRM under DTC is smoother. The rise-up time in DTC is less than $0.1 \mathrm{~s}$ while that in CCC is more than $0.1 \mathrm{~s}$, which means that the SSRM under DTC control has faster acceleration.

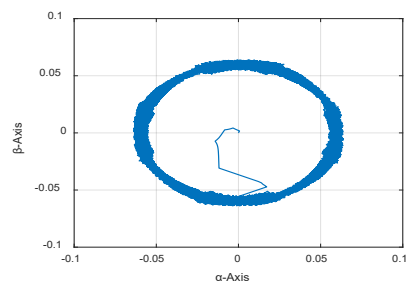

(a)

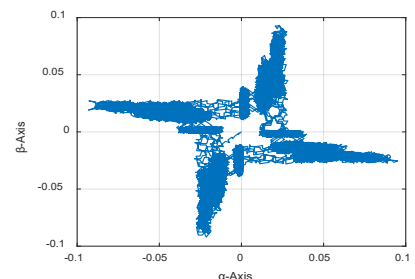

(b)
Fig. 16. Comparison of flux linkage vector locus when load torque changes from $3 \mathrm{Nm}$ to $6 \mathrm{Nm}$. (a) DTC and (b) CCC under $3 \mathrm{Nm}$ at $200 \mathrm{r} / \mathrm{min}$.

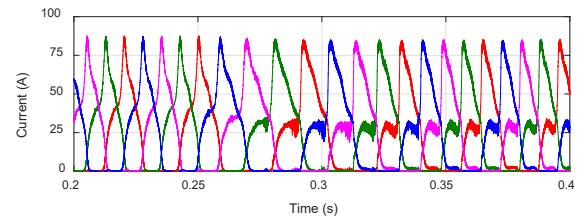

(a)

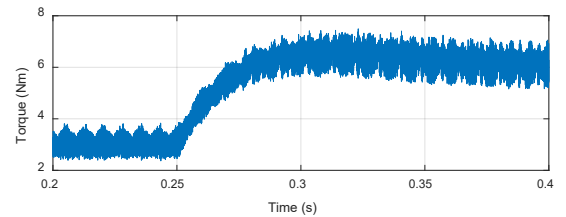

(b)

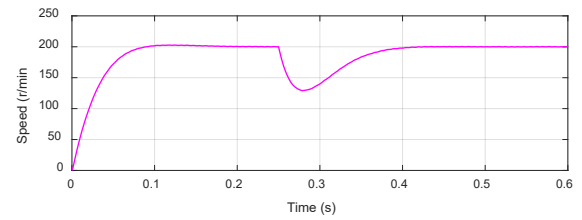

(c)

Fig. 17. Simulation results of DTC when the load torque changes from $3 \mathrm{Nm}$ to $6 \mathrm{Nm}$ at $200 \mathrm{r} / \mathrm{min}$. (a) Current. (b) Torque. (c) Speed.

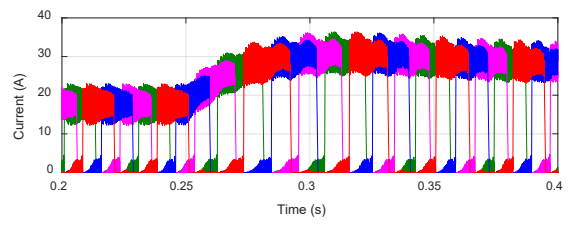

(a)

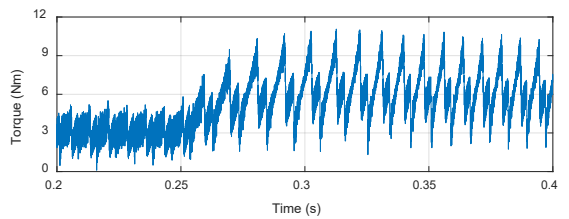

(b)

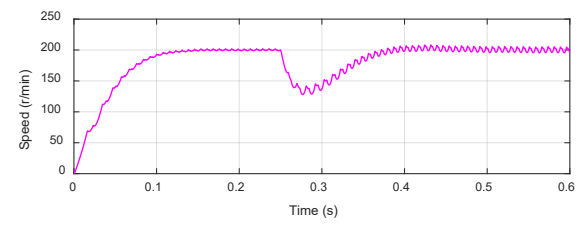

(c)

Fig. 18. Simulation results of DTC when the load torque changes from $3 \mathrm{Nm}$ to $6 \mathrm{Nm}$ at $200 \mathrm{r} / \mathrm{min}$. (a) Current. (b) Torque. (c) Speed. 
In order to further compare the performances under $\mathrm{CCC}$ and DTC methods, overall performances at $200 \mathrm{r} / \mathrm{min}$ when the load torque changes from $3 \mathrm{Nm}$ to $6 \mathrm{Nm}$ have been investigated. The change of load torque occurs at $0.25 \mathrm{~s}$. The flux linkage vector under this situation is shown in Fig. 16, and the given flux linkage value is $0.06 \mathrm{~Wb}$. Similar with Fig. 13, it can be seen that the amplitude of flux linkage under DTC is basically the same even if the load torque is changed. However, the amplitude in flux linkage with CCC mode has turned from 0.06 $\mathrm{Wb}$ to $0.09 \mathrm{~Wb}$ as the load torque is changed.

Figs. 17 and 18 show the current, torque and speed waveforms when the load torque changes from $3 \mathrm{Nm}$ to $6 \mathrm{Nm}$ at $0.25 \mathrm{~s}$ under DTC and CCC methods, respectively. From Fig. 17(a) and Fig. 18(a), it can be seen that the peak current in DTC is almost the same before and after the torque mutation, and the reference current in CCC obviously turns from $20 \mathrm{~A}$ to $30 \mathrm{~A}$. When the torque reaches a steady state after the torque mutation, the maximum and minimum values in DTC are 7.05 $\mathrm{Nm}$ and $5.06 \mathrm{Nm}$ and those in CCC are $10.46 \mathrm{Nm}$ and $1.33 \mathrm{Nm}$. the torque ripple in DTC is change from $57.28 \%$ to $33.06 \%$, while that in CCC is changed from $175.58 \%$ to $152.68 \%$. The torque ripples under the two control methods are decreased with the increase of load torque. However, torque ripple in DTC system is reduced by $42.28 \%$ while that in CCC system is just reduced by $13.04 \%$. Thus, DTC is more conductive to reducing the torque ripple compared with $\mathrm{CCC}$ system with the enlargement of load torque. As shown in Fig. 17(c) and Fig. 18(c), both control methods can restore the SSRM to the stable speed under the disturbance. The changes in speed are almost the same and the two methods spend about $0.15 \mathrm{~s}$ to return to the normal speed. Besides, the speed vibration after the change of torque with CCC mode becomes lager than before while that with DTC mode is same as before.

TABLE V

Summary of Performances of the Two Control Methods

\begin{tabular}{lcccc}
\hline \hline & \multicolumn{2}{c}{ DTC } & \multicolumn{2}{c}{ CCC } \\
\cline { 2 - 5 } Load torque $(\mathrm{Nm})$ & 3 & 6 & 3 & 6 \\
\hline Speed (r/min) & 200 & 200 & 200 & 200 \\
RMS phase current (A) & 28.37 & 32.13 & 11.40 & 18.65 \\
Peak phase current (A) & 73.29 & 83.45 & 23.08 & 33.80 \\
Maximum torque (Nm) & 3.90 & 7.05 & 5.62 & 10.46 \\
Minimum torque $(\mathrm{Nm})$ & 2.17 & 5.06 & 0.30 & 1.33 \\
Average torque $(\mathrm{Nm})$ & 3.02 & 6.02 & 3.03 & 5.98 \\
Torque ripple $(\%)$ & 57.28 & 33.06 & 175.58 & 152.68 \\
Torque per ampere $(\mathrm{Nm} / \mathrm{A})$ & 0.11 & 0.19 & 0.26 & 0.32 \\
\hline \hline
\end{tabular}

More detailed data are shown in Table V. In summary, compared with CCC method, DTC exhibits better performance in torque ripple reduction. Although both the two methods can decrease the value of torque ripple with the enlargement of load torque, the effect of DTC is more effective. On the other hand, it can be seen in Table V, torque per ampere of SSRM under DTC is lower than that under CCC. And the differences of torque per ampere between the two method are reduced as the load torque increases.

\section{EXPERIMENT VALIDATION}

The experiment platform of the SSRM is shown in Fig. 19. The parameters of key elements are presented in Table VI. The tested 16/10 SRSRM, torque and speed sensor, and magnetic power brake are connected by two couplings. The position is detected by the Hall sensor ATS675LSE. The signals captured by the position and current sensors are sent to the dSPACE. The DTC and CCC strategies are implemented by dSPACE.

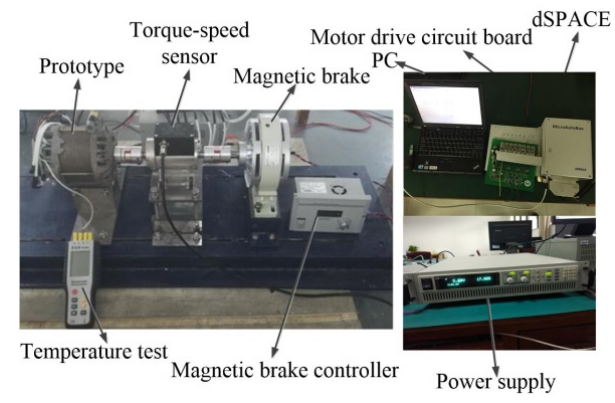

Fig. 19. Experiment platform of the SSRM.

TABLE VI

PARAMETERS OF THE KEy ELEMENTS

\begin{tabular}{|c|c|c|}
\hline Key elements & Key parameters & Value \\
\hline Intelligent power module & Maximum of frequency & $21 \mathrm{kHz}$ \\
\hline (IR2101) & Operating frequency & $16 \mathrm{kHz}$ \\
\hline $\begin{array}{l}\text { Oscilloscope } \\
(\mathrm{MSOX} 4024 \mathrm{~A})\end{array}$ & Maximum sampling rate & $5 \mathrm{MHz}$ \\
\hline $\begin{array}{l}\text { Magnetic powder brake } \\
\text { (JN338) }\end{array}$ & $\begin{array}{l}\text { Maximum of braking } \\
\text { torque }\end{array}$ & $300 \mathrm{Nm}$ \\
\hline
\end{tabular}

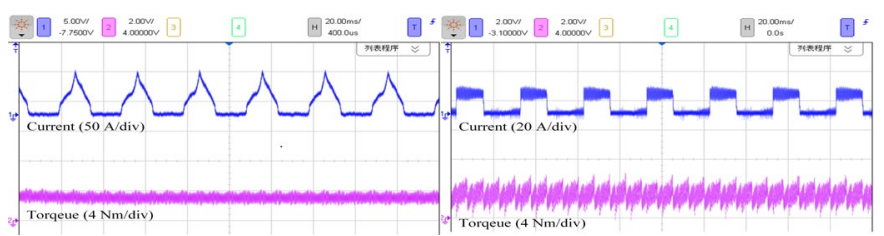

(a)

(b)

Fig. 20. Current and torque waveforms with (a) DTC and (b) CCC modes under $3 \mathrm{Nm}$ at $200 \mathrm{r} / \mathrm{min}$.

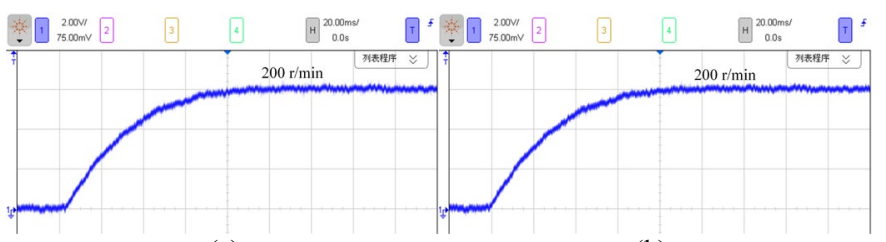

(a)

(b)

Fig. 21. Speed response under $3 \mathrm{Nm}$ at $200 \mathrm{r} / \mathrm{min}$. (a) DTC. (b) CCC.

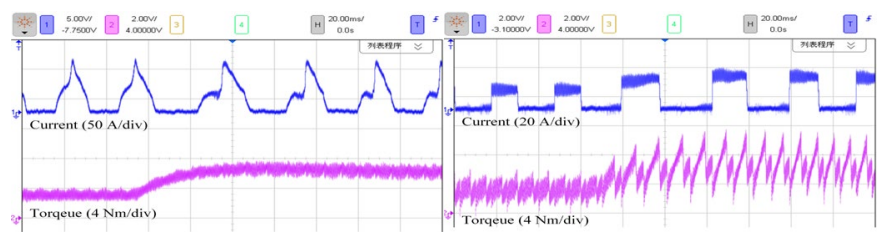

(a)

(b)

Fig. 22. Current and torque waveforms with (a) DTC and (b) CCC modes when the lord torque changes from $3 \mathrm{Nm}$ to $6 \mathrm{Nm}$ at $200 \mathrm{r} / \mathrm{min}$. 


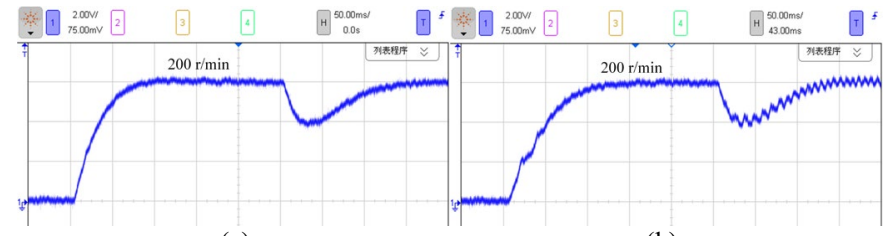

(a)

(b)

Fig. 23. Speed response when the lord torque changes from $3 \mathrm{Nm}$ to $6 \mathrm{Nm}$ at $200 \mathrm{r} / \mathrm{min}$.

Experimental results of torque and current characteristics with DTC and CCC modes under $3 \mathrm{Nm}$ at $200 \mathrm{r} / \mathrm{min}$ are shown in Fig. 20. The average torque with DTC mode is $3.05 \mathrm{Nm}$, and its tipple is $56.06 \%$. The average torque with CCC mode is 3.07 $\mathrm{Nm}$, and it ripple is $173.29 \%$. The data of experiment is close to the simulation results, and it can be seen that DTC can greatly reduce the torque ripple. Corresponding speed responses of the two modes under the same condition are shown in Fig. 21. The same conclusion can be drawn that the speed of SSRM under DTC can rise up more smoothly, and it requires less time than that under CCC.

Fig. 22 shows the experimental results of torque and current characteristics with DTC and CCC modes when the load torque changes from $3 \mathrm{Nm}$ to $6 \mathrm{Nm}$ at the time of $0.25 \mathrm{~s}$. It can be seen that even the load torque has been changed, the torque under DTC is well controlled around the $6 \mathrm{Nm}$. the torque ripple after the change of load torque under DTC is about $34.11 \%$ while that under $\mathrm{CCC}$ is about $153.06 \%$. Speed responses under this situation are shown in Fig. 23. The speed vibration under CCC is larger than that under DTC, and the charge of torque has more effects on the speed vibration under CCC.

\section{VI.CONCLUSION}

In this paper, a novel modeling method which contains the torque-balanced method, fourth-order Fourier series and Kriging model is used to approximate the flux linkage and torque models for the SSRM. The torque-balanced method is used to measure the flux linkage values at five balanced positions and the flux linkage and torque characteristics of the SSRM are firstly expressed by the fourth-order Fourier series based on the measured data. Then, the Kriging model is introduced for the further nonlinear modeling of the SSRM. The created model is applied into the DTC and CCC control for the SSRM. The simulation results of the SSRM based on the DTC and CCC systems are compared. Base on simulation results and experimental validation, five main conclusions can be drawn as follows.

1) The amplitude of flux linkage in DTC can be well controlled even the load torque has changed, while that in $\mathrm{CCC}$ is increased with the enlargement of load torque under the same speed.

2) Compared with CCC method, DTC can greatly reduce the torque ripple. Besides, with the enlargement of load torque, DTC can reduce the torque ripple more effectively.

3) The SSRM under DTC method can startup more smoothly and the startup time is less than that under CCC method.

4) The toque ampere of SSRM under DTC is lower than that under CCC, but the differences are decreased as the load torque increases.

5) Both the DTC and CCC methods can restore the SSRM to the stable speed when the load torque changes from $3 \mathrm{Nm}$ to 6 Nm. During the process, the speed oscillation under DTC system is smaller.

\section{REFERENCES}

[1] J. Ye, P. Malysz, and A. Emadi, "A fixed-switching-frequency integral sliding mode current controller for switched reluctance motor drives," IEEE J. Emerg. Sel. Top. Power Electron., vol. 3, no. 2, pp. 381-394, Jun. 2015.

[2] X. Sun, C. Hu, Gang Lei, Y. Guo, and J. Zhu, "State feedback control for a PM hub motor based on grey wolf optimization algorithm," IEEE Trans. Power Electron., vol. 35, no. 1, pp. 1136-1146, Jan. 2020.

[3] X. Zhu, J. Huang, L. Quan, Z. Xiang, and B. Shi, "Comprehensive sensitivity analysis and multi-objective optimization research of permanent magnet flux-intensifying motors," IEEE Trans. Ind. Electron., vol. 66, no. 4, pp. 2613-2627, Apr. 2019.

[4] S. Saponara, P. Tisserand, P. chassard, and D. M. Ton, "Design and measurement of integrated converters for belt-driven starter-generator in $48 \mathrm{~V} \mathrm{micro/mild} \mathrm{hybrid} \mathrm{vehicles,"} \mathrm{in} \mathrm{Proc.} \mathrm{IEEE} \mathrm{Int.} \mathrm{Conf.} \mathrm{on}$ Environment and Electrical Engineering (ICEEC 2017), vol. 53, no. 4, pp. 3936-3949, Jul. 2017.

[5] Q. Chen, G. Xu, G. Liu, W. Zhao, L. Liu, and Z. Lin, "Torque Ripple Reduction in Five-Phase IPM Motors by Lowering Interactional MMF," IEEE Trans. Ind. Electron., vol. 65, no. 11, pp. 8520-8531, Nov. 2018.

[6] X. Zhu, D. Fan, Z. Xiang, L. Quan, W. Hua, and M. Cheng, "Systematic multi-level optimization design and dynamic control of less-rare-earth hybrid permanent magnet motor for all-climatic electric vehicles," Applied Energy, DOI: 10.1016/j.apenergy.2019.113549.

[7] X. Sun, J. Cao, G. Lei, Y. Guo, and J. Zhu. "Speed sensorless control for permanent magnet synchronous motors based on finite position set," IEEE Trans. Ind. Electron., 2019, DOI: 10.1109/TIE.2019.2947875.

[8] M. Duran, I. Gonzaiez-Prieto, N. Rios, and F. Barrero, "A simple, fast and robust open-phase fault detection technique for six-phase induction motor drives," IEEE Trans. Power Electron., vol. 33, no. 1, pp. 547-557, Jan. 2018.

[9] M. Messaoudi and L. Sbita, "Sensorless direct torque and flux control of induction motor based on MRAS and luenberger observer," in proc. IEEE Int. Conf. on Green Energy Conversion Systems (GECS 2017), pp. 1-7, Mar. 2017.

[10] X. Guo, R. Zhong, M. Zhang, D. Ding, W. Sun, et al., "Fast computation of radial vibration in switched reluctance motors," IEEE Trans. Ind. Electron., vol. 65, no. 6, pp. 4588-4598, Jun. 2018.

[11] J. Ye, B. Bilgin, and A. Emadi, "An extended-speed low-ripple torque control of switched reluctance motor drives," IEEE Trans. Power Electron., vol. 30, no. 3, pp. 1457-1470, Mar. 2015.

[12] X. Sun, Y. Shen, S. Wang, G. Lei, Z. Yang, and S. Han, "Core losses analysis of a novel $16 / 10$ segmented rotor switched reluctance BSG motor for HEVs using nonlinear lumped parameter equivalent circuit model," IEEE/ASME Trans. Mechatronics, vol. 23, no. 2, pp. 747-757, Apr. 2018.

[13] S. Marinkov and B. D. Jager, "Four-quadrant control of $4 / 2$ switched reluctance machines," IEEE Trans. Ind. Electron., vol. 63, no. 12, pp. 7393-7403, Dec. 2016.

[14] J. Oyama, T. Higuchi, T. Abe, and K. Tanaka, "The fundamental characteristics of novel switched reluctance motor with segment core embedded in aluminum rotor block," in Proc. Int. Conf. on Electrical Machines and Systems (ICEMS 2005), Vol. 1, pp. 515-519, Sep. 2005.

[15] X. Sun, K. Diao, G. Lei, Y. Guo, and J. Zhu, "Real-time HIL emulation for a segmented-rotor switched reluctance motor using a new magnetic equivalent circuit," IEEE Trans. Power Electron., 2019, DOI: 10.1109/TPEL.2019.2933664.

[16] X. Sun, K. Diao, and Z. Yang. "Performance improvement of a switched reluctance machine with segmental rotors for hybrid electric vehicles." Comput. Electr. Eng., vol. 77, pp. 244-259, Jul. 2019.

[17] H. Cheng, H. Chen, and Z. Yang, "Average torque control of switched reluctance machine drives for electric vehicles," IET Electric Power Applications, vol. 9, no. 7, pp. 459-468, Jul. 2015.

[18] Y. Guo, Q. Ma, and W. Ye, "Comparative study on torque ripple suppression method of three-phase 6/4 switched reluctance motor," in 
Proc. IEEE Int. Conf. on Aircraft Utility Systems (AUS 2016), pp. 356-361, Oct. 2016

[19] M. Dong, "Research on reduction the torque ripple in switched reluctance motor," in Proc. IEEE Int. Symp. on Computer, Consumer and Control (IS3C 2016), pp. 1071-1074, Jul. 2016.

[20] J. Cai, Z. Q. Deng, R. Y. Qi, Z. Y. Liu, and Y. H. Cai, "A novel bvc-rbf neural based on system simulation model for switched reluctance motor," IEEE Trans. Magn., vol. 47, no. 4, pp. 830-838. Jul. 2011.

[21] W. Ding, and D. Liang, "Modeling of a 6/4 Switched Reluctance Motor Using Adaptive Neural Fuzzy Inference System," IEEE Trans. Magn., vol. 44, no. 7, pp. 1796-1804. Jul. 2008.

[22] K. Lu, P. O. Rasmussen, and A. E. Ritchie, "Investigation of flux-linkage profile measurement methods for switched-reluctance motors and permanent-magnet motors," IEEE Trans. Instrum. \& Meas., vol. 58, no. 9, pp. 3191-3198, Oct. 2009.

[23] L. Shen, J. Wu, S. Yang, and X. Huang, "Fast Flux Linkage Measurement for Switched Reluctance Motors Excluding Rotor Clamping Devices and Position Sensors," IEEE Trans. Instrum. Meas., vol. 62, no.1, pp. 185-191. Jan. 2013.

[24] S. Song, L. Ge, and M. Zhang, "Data-reconstruction-based modeling of SRM with few flux-linkage samples from torque-balanced measurement," IEEE Trans. Energy Convers., vol. 31, no. 2, pp. 424-435, Jun. 2016

[25] Z. Hu, Y. Li, and K. Wang, "Torque ripple reduction of SRM based on direct torque control," Machine Electrical \& Apparatus, vol. 35, no. 3, pp. 34-39, Jul. 2016.

[26] J. Ye, B. Bilgin, and A. Emadi, "An extended-speed low-ripple torque control of switched reluctance motor drives," IEEE Trans. Power Electron., vol. 30, no. 3, pp. 1457-1470, Mar. 2015

[27] A. Khalil, and I. Husain, "A Fourier Series Generalized Geometry-Based Analytical Model of Switched Reluctance Machines," IEEE Trans. Indus. Appl., vol. 43, no. 3, pp. 673-684. May/Jun. 2007.

[28] G. Lei, K. R. Shao, Y. G. Guo, J. G. Zhu, and J. D. Lavers, "Sequential optimization method for the design of electromagnetic device," IEEE Trans. Magn., vol. 44, no. 11, pp. 3217-3220, Nov. 2008.

[29] X. Sun, K. Diao, G. Lei, Y. Guo, and J. Zhu, "Study on segmented-rotor switched reluctance motors with different rotor pole numbers for BSG system of hybrid electric vehicles," IEEE Trans. Veh. Technol., vol. 68 , no. 6, pp. 5537-5547, Jun. 2019.

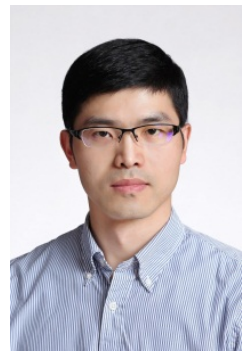

Xiaodong Sun (M'12-SM'18) received the B.Sc. degree in electrical engineering, and the M.Sc. and Ph.D. degrees in control engineering from Jiangsu University, Zhenjiang, China, in 2004, 2008 , and 2011, respectively.

Since 2004, he has been with Jiangsu University, where he is currently a Professor with the Automotive Engineering Research Institute. From 2014 to 2015, he was a Visiting Professor with the School of Electrical, Mechanical, and Mechatronic Systems, University of Technology Sydney, Sydney, Australia. His current teaching and research interests include electrical machines and drives, drives and control for electric vehicles, and intelligent control. $\mathrm{He}$ is the author or coauthor of more than 80 refereed technical papers and one book, and he is the holder of 36 patents in his areas of interest.

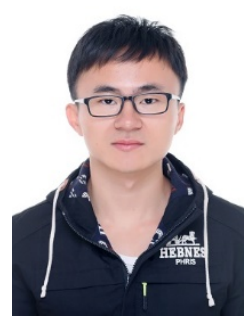

Kaikai Diao (S'18) was born in Zhenjiang, Jiangsu, China, in 1994. He received the B.S. degree in vehicle engineering from Jiangsu University, Zhenjiang, China, in 2017, and he is currently working toward the Ph.D. degree in Jiangsu University, Zhenjiang, China.

His current research interests include design, optimization, magnetic equivalent circuits modeling, control, and loss analysis of switched reluctance motors for automobile application.

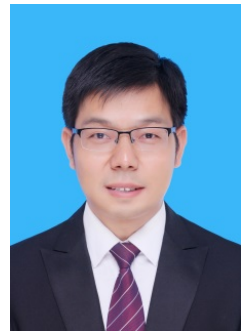

Zebin Yang received the B.Sc., M.Sc. and Ph.D. degrees in electrical engineering from Jiangsu University, Zhenjiang, China, in 1999, 2004, and 2013, respectively. where he is currently a professor in Jiangsu University. From 2014 to 2015, he was a Visiting Scholar with the School of Electrical, Mechanical, and Mechatronic Systems, University of Technology Sydney, Sydney, Australia. His main research interests include drives and control for bearingless motors and magnetic levitation transmission technology.

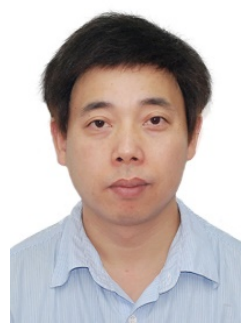

Gang Lei (M'14) received the B.S. degree in Mathematics from Huanggang Normal University, China, in 2003, the M.S. degree in Mathematics and Ph.D. degree in Electrical Engineering from Huazhong University of Science and Technology, China, in 2006 and 2009, respectively. $\mathrm{He}$ is currently a senior lecturer at the School of Electrical and Data Engineering, University of Technology Sydney (UTS), Australia. His research interests include design optimization and control of electrical drive systems and renewable energy systems.

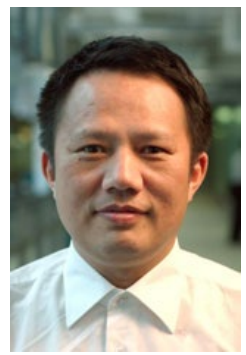

Youguang Guo (S'02-M'05-SM'06) received the B.E. degree from Huazhong University of Science and Technology, China in 1985, the M.E. degree from Zhejiang University, China in 1988, and the Ph.D. degree from University of Technology, Sydney (UTS), Australia in 2004, all in electrical engineering. He is currently a professor at the School of Electrical and Data Engineering, University of Technology Sydney (UTS). His research fields include measurement and modeling of properties of magnetic materials, numerical analysis of electromagnetic field, electrical machine design optimization, power electronic drives and control.

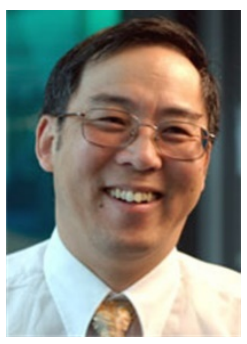

Jianguo Zhu (S'93-M'96-SM'03) received the B.E. degree in 1982 from Jiangsu Institute of Technology, Jiangsu, China, the M.E. degree in 1987 from Shanghai University of Technology, Shanghai, China, and the Ph.D. degree in 1995 from the University of Technology Sydney (UTS), Sydney, Australia, all in electrical engineering. $\mathrm{He}$ was appointed a lecturer at UTS in 1994 and promoted to full professor in 2004 and Distinguished Professor of Electrical Engineering in 2017. At UTS, he has held various leadership positions, including the Head of School for School of Electrical, Mechanical and Mechatronic Systems and Director for Centre of Electrical Machines and Power Electronics. In 2018, he joined the University of Sydney, Australia, as a full professor and Head of School for School of Electrical and Information Engineering. His research interests include computational electromagnetics, measurement and modelling of magnetic properties of materials, electrical machines and drives, power electronics, renewable energy systems and smart micro grids. 